\title{
Study of Metallofullerenes Encapsulating Actinides
}

\author{
Kazuhiko Akiyama, ${ }^{\text {,a,b }}$ Keisuke Sueki, ${ }^{a}$ Kazuaki Tsukada,b ${ }^{\text {Tsuyoshi Yaita, }}{ }^{\text {b }}$ Yoko Miyake, \\ Hiromitsu Haba, ${ }^{\mathrm{b}}$ Masato Asai, ${ }^{\mathrm{b}}$ Takeshi Kodama, ${ }^{\mathrm{a}}$ Koichi Kikuchi, ${ }^{\mathrm{a}}$ Tsutomu Ohtsuki, \\ Yuichiro Nagame, ${ }^{\text {b }}$ Motomi Katada, ${ }^{a}$ and Hiromichi Nakahara ${ }^{a}$ \\ ${ }^{a}$ Graduate School of Science, Tokyo Metropolitan University, Hachioji, Tokyo 192-0397, Japan \\ ${ }^{\mathrm{b}}$ Advanced Science Research Center, Japan Atomic Energy Research Institute, Tokai, Ibaraki 319-1195, \\ Japan \\ ${ }^{c}$ Laboratory of Nuclear Sciences, Tohoku University, Sendai, Miyagi 980-8577, Japan
}

\section{Received: March 17, 2002; In Final Form: May 1, 2002}

The oxidation state of actinide elements encapsulated in fullerenes is studied. HPLC elution behavior of actinide fullerenes is classified into two groups; the elution behavior of the first group, encapsulating $\mathrm{U}, \mathrm{Np}$, and Am, is similar to that of the light lanthanide fullerenes, such as $\mathrm{La}, \mathrm{Ce}, \mathrm{Pr}$, and $\mathrm{Nd}$, while the behavior of the second group, encapsulating $\mathrm{Th}$ and $\mathrm{Pa}$, is quite different from that of any lanthanide fullerenes. The chemical species in the main HPLC elution peak of each group were identified as $M @ \mathrm{C}_{82}$ and $\mathrm{M} @ \mathrm{C}_{84}(\mathrm{M}=$ metal atom) from the mass of the $\mathrm{U}$ and $T h$ fullerenes, respectively. The oxidation states of the $U$ and $T h$ atoms in the fullerenes were deduced to be $3+$ and $4+$, respectively, from the UV/vis/NIR absorption and XANES spectroscopy.

\section{Introduction}

Since the discovery of fullerenes by Kroto and Smalley, ${ }^{1}$ the molecules with the special cage structure have been attracting interests of many scientists as a new functional material. The size of the inner space of this cage is about $7 \AA$ in diameter for the smallest fullerene, $\mathrm{C}_{60}$, and is sufficiently spacious to take several atoms or a small cluster inside. In addition, it has been pointed out ${ }^{2-16}$ that the atmosphere of this inner space is very reductive owing to the existence of many unsaturated $\pi$ orbitals from the carbon atoms that form the cage structure. For example, the lanthanide elements of $\mathrm{Sm}, \mathrm{Eu}, \mathrm{Tm}$, and $\mathrm{Yb}$, which take commonly $3+$ oxidation state in solid compounds and in aqueous solutions, take $2+$ oxidation state in the fullerene cage. This fact indicates that the inner space of the fullerene is so reductive that the encapsulated atom is stabilized with its lower oxidation state for a long period.

Among the $f$-block elements, the actinide elements are known to take various oxidation states depending on the surrounding environments. It is, therefore, interesting from the view point of the actinide science to investigate the oxidation state of the actinide elements in the reductive environment such as the inside of fullerene cages. In this paper, we discuss the oxidation state of actinide elements in fullerene cages.

\section{Experimental Procedures}

2.1. Preparation and HPLC Separation of Actinide Metallofullerenes. The soot mixture including actinide metallofullerenes was produced by the arc-discharge method using a carbon rod which was impregnated with radioactive tracers, ${ }^{234} \mathrm{Th},{ }^{233} \mathrm{~Pa},{ }^{237} \mathrm{U},{ }^{239} \mathrm{~Np}$, and ${ }^{240} \mathrm{Am}$, and $\mathrm{La}\left(\mathrm{NO}_{3}\right)_{3}$ as a carrier. The atom ratio for $\mathrm{C} / \mathrm{La}$ was set to be $100 / 1$. The condition of the arc-discharge was the same as that described in Reference 17 . The crude fullerene including the metallofullerenes was extracted by $\mathrm{CS}_{2}$ from the primary soot and then re-dissolved in toluene for the injection into HPLC columns of Buckyprep (10 $\mathrm{mm} \phi \times 250 \mathrm{~mm})$ and 5PBB $(10 \mathrm{~mm} \phi \times 250 \mathrm{~mm})$. The Buckyprep and 5PBB columns were operated with the flow rate of 3.2 and $6.0 \mathrm{~mL} / \mathrm{min}$, respectively. The effluent from the column was collected for every $1 \mathrm{~min}$ and monitored by an on-line UV absorption detector. The HPLC elution behavior of the actinide metallofullerenes was monitored by the off-line detection of $\gamma$ and $X$ rays from the actinide radio-

*Corresponding author. E-mail: kakiyama@popx.tokai.jaeri.go.jp. FAX: +81-29-282-5939. tracers. For an examination of physico-chemical properties of the actinide fullerenes, macroscopic quantities of $T h$ and $U$ metallofullerenes were also prepared by the carbon rods containing a few grams of $T h$ and $U$ instead of the La carrier. The purification of these metallofullerenes was performed by collecting the HPLC fractions that contained the main species of Th and U metallofullerenes according to the result of the radiotracer experiment on the Buckyprep and 5PBB columns.

2.2. UV/vis/NIR Absorption and XANES Spectroscopy of Th and $U$ Metallofullerenes. The UV/vis/NIR absorption spectroscopy and the XANES (X-ray Absorption Near Edge Structure) spectroscopy were performed for the purified main species of the Th and $U$ metallofullerenes to investigate the electronic state of these species. These metallofullerenes dissolved in toluene were put in the quartz cell $(10 \mathrm{~mm}$ light path and $2 \mathrm{~mm}$ width) for the observation of the UV/vis/NIR absorption spectra in the wavelength region of $400 \mathrm{~nm}$ to $1600 \mathrm{~nm}$. To take the Th $\mathrm{L}_{\mathrm{III}}$-edge and $\mathrm{U}_{\mathrm{III}}$-edge XANES spectra, the samples were prepared by dropping the $\mathrm{CS}_{2}$ solutions on the crystal plates with a shallow dip in the center and then dried. The absorption spectra were taken at the photon factory of KEK in Tsukuba using a Si(111) single crystal monochromator. All the XANES spectra were acquired in the fluorescence mode using a Ge detector.

\section{Results and Discussion}

3.1. HPLC Elution Behavior of Actinide Metallofullerenes. Figures 1(a) and (b) show the HPLC elution curves of the actinide metallofullerenes observed with the Buckyprep and 5PBB columns, respectively. It was found that the HPLC elution behavior was classified into two groups from the position of the elution peaks. The position of the elution peaks of the first group, encapsulating $\mathrm{U}, \mathrm{Np}$, and $\mathrm{Am}$, is identical to that of the light lanthanide fullerenes, such as $\mathrm{La}$, $\mathrm{Ce}, \mathrm{Pr}$, and $\mathrm{Nd}^{2,18-20}$ In the second group, encapsulating $\mathrm{Th}$ and $\mathrm{Pa}$, the elution curves are completely different from those of any lanthanides.

For the Buckyprep column, the elution behavior of fullerenes is ruled by both the number of $\pi$ electrons on the cage and the symmetry of the fullerene cage, whereas in the 5PBB column the fullerenes are mainly separated by the number of $\pi$ electrons of the cage and the symmetry of the cage does not affect the separation so much. The similarity of the retention time of the main species of $\mathrm{U}, \mathrm{Np}$, and Am metallofullerenes with that of some lanthanides indicates that these main species have the same car- 
bon number, symmetric structure, and charge on the cage. For the lanthanide species, these main species have been assigned as $\mathrm{M} @ \mathrm{C}_{82}$ which encapsulates a trivalent lanthanide cation. The main species of $U$ metallofullerene was actually identified as U@ $\mathrm{C}_{82}$ by TOF/MS (Time of Flight/Mass Spectroscopy). ${ }^{21}$ Accordingly, this result suggests that the oxidation state of the actinides encapsulated as $\mathrm{M} @ \mathrm{C}_{82}$ is identical to that of the lanthanides in $\mathrm{M} @ \mathrm{C}_{82}$. On the other hand, the retention time of metallofullerenes of $\mathrm{Th}$ and $\mathrm{Pa}$ was found to be about $5 \mathrm{~min}$ longer in the 5PBB column, and 30 min longer in the Buckyprep column compared to those for the above-stated group. The main component of the elution peak for the $\mathrm{Pa}$ species is considered to be $\mathrm{M} @ \mathrm{C}_{84}$ type metallofullerene like Th@ $\mathrm{C}_{84}$ which was identified by the TOF/MS measurement. ${ }^{22}$ Stevenson et al. reported the correlation between the retention time and the number of electrons on the fullerene cage for $5 \mathrm{PBB}$ column separation. ${ }^{23}$ The retention time of $\mathrm{M} @ \mathrm{C}_{84}$ has been known only for $\mathrm{Sm}, \mathrm{Eu}$, $\mathrm{Tm}$, and $\mathrm{Yb}$ species whose charge on the cage has been revealed to be 2-. These $\mathrm{M} @ \mathrm{C}_{84}$ can accept extra two electrons on the $\mathrm{C}_{84}$ cage and the retention time of these species is nearly equal to that of the hollow $\mathrm{C}_{86}$. While the retention time of the $\mathrm{M} @ \mathrm{C}_{84}$ for $\mathrm{Th}$ and $\mathrm{Pa}$ is slightly longer than that of the former $\mathrm{M} @ \mathrm{C}_{84}$ species. According to the Stevenson's concept, the number of $\pi$ electrons on the cage of $\mathrm{M} @ \mathrm{C}_{84}$ for $\mathrm{Th}$ and $\mathrm{Pa}$ is deduced to be greater than that of the former $\mathrm{M} @ \mathrm{C}_{84}$.

3.2. Spectroscopic Properties of $T$ h@ $\mathrm{C}_{84}$ and $\mathrm{U} @ \mathrm{C}_{82}$. Figures 2(a) and 2(b) show the UV/vis/NIR absorption spectra of the isolated $\mathrm{U} @ \mathrm{C}_{82}$ and $\mathrm{Th} @ \mathrm{C}_{84}$ in toluene, respectively. The $\mathrm{U} @ \mathrm{C}_{82}$ spectrum in Figure 2(a) has three characteristic absorption peaks at the wavelengths of $619 \mathrm{~nm}, 977 \mathrm{~nm}$, and $1352 \mathrm{~nm}$ which coincide well with those of $\mathrm{M} @ \mathrm{C}_{82}$ of the trivalent lanthanides as shown in Figure 2(c). ${ }^{24}$ This similarity strongly sug-

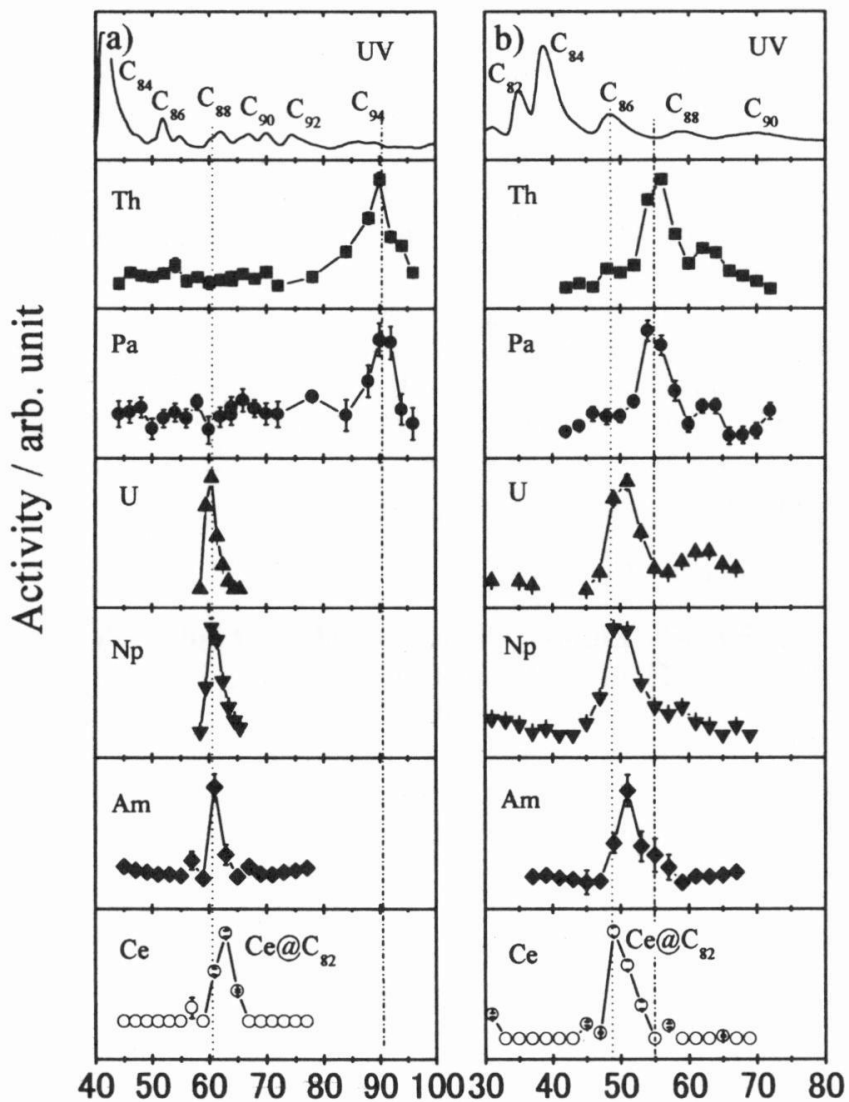

\section{Retention Time /min}

Figure 1. HPLC elution curves of actinide metallofullerenes on (a) the Buckyprep column and (b) the 5PBB column. For both columns, the elution curves of $\mathrm{U}, \mathrm{Np}$, and Am metallofullerenes are similar to those of the light lanthanide fullerenes such as $\mathrm{Ce}$. On the other hand, the elution curves of $\mathrm{Th}$ and $\mathrm{Pa}$ metallofullerenes are quite different from those of the any lanthanide metallofullerenes. ${ }^{22}$ gests that the charge of the $\mathrm{C}_{82}$ cage of the $\mathrm{U} @ \mathrm{C}_{82}$ is $3-$. In addition, it is interesting that the replacement of encapsulated metal from lanthanide to uranium does not affect the absorption peaks of $\mathrm{M} @ \mathrm{C}_{82}$.

Up to now, the UV/vis/NIR spectrum of the isolated $\mathrm{M} @ \mathrm{C}_{84}$ is measured only for $\mathrm{Sm}$ which are shown in Figure 2(d). Okazaki et al. reported that $\mathrm{Sm} @ \mathrm{C}_{84}$ has three topologically different isomers and they determined the oxidation state of $\mathrm{Sm}$ in $\mathrm{C}_{84}$ to be divalent from the electron energy loss spectroscopy (EELS). ${ }^{25}$ The $\mathrm{C}_{84}$ fullerene cage is expected to have 24 structural isomers which satisfy IPR. ${ }^{26}$ Considering the number of the isomers of the air stable $\mathrm{Sm} @ \mathrm{C}_{84}$, it can be assumed that the three of those $\mathrm{C}_{84}$ would be stabilized as the $\mathrm{C}_{84}^{2-}$. If the $\mathrm{UV} / \mathrm{vis} / \mathrm{NIR}$ absorption spectrum of $\mathrm{M} @ \mathrm{C}_{84}$ were not so much affected by the encapsulated metal atom like the $\mathrm{M} @ \mathrm{C}_{82}$ case, the observed difference in the absorption spectra between $\mathrm{Sm}$ and Th supports that the charge of the $\mathrm{C}_{84}$ cage of $\mathrm{Th} @ \mathrm{C}_{84}$ is not divalent.

To confirm the oxidation state of the $\mathrm{U}$ and $\mathrm{Th}$ atoms in the metallofullerene, $\mathrm{U} \mathrm{L}_{\mathrm{III}}$-edge and Th $\mathrm{L}_{\mathrm{III}}$-edge XANES spectra were examined as shown in Figures 3(a) and 3(b) together with the reference materials of $\mathrm{UCl}_{3}, \mathrm{UO}_{2}$, and $\mathrm{Th}\left(\mathrm{NO}_{3}\right)_{4} \cdot 2 \mathrm{H}_{2} \mathrm{O}$. The $\mathrm{U} \mathrm{L}_{\mathrm{III}}$-edge spectrum of $\mathrm{U} @ \mathrm{C}_{82}$ is clearly shifted to lower energy side in comparison with that of $\mathrm{UO}_{2}$. To make clear the difference between these spectra, the edge energy was evaluated by fitting the spectra with a Gaussian plus arctangent function (the inflection point of the arctangent function is defined as $E_{0}$ ). The $E_{0}$ of $\mathrm{U} @ \mathrm{C}_{82}$ was found to be shifted to lower energy side by $5 \mathrm{eV}$ in comparison with that of $\mathrm{UO}_{2}$ and is nearly equal to that of $\mathrm{UCl}_{3}$. From the results of the HPLC investigation, $\mathrm{UV} / \mathrm{vis} / \mathrm{NIR}$, and XANES spectroscopy, it is concluded that the oxidation state of the $\mathrm{U}$ atom encapsulated in the $\mathrm{C}_{82}$ cage is $3+$, and the charge coupling in $\mathrm{U} @ \mathrm{C}_{82}$ is suggested to be $\mathrm{U}^{3+} @ \mathrm{C}_{82}^{3-}$.

The $E_{0}$ of the Th $\mathrm{L}_{\mathrm{III}}$-edge spectrum for $\mathrm{Th} @ \mathrm{C}_{84}$ also shows a small shift to the lower energy side by about $3 \mathrm{eV}$ compared with that of the reference material of $\mathrm{Th}\left(\mathrm{NO}_{3}\right)_{4} \cdot 2 \mathrm{H}_{2} \mathrm{O}$. To con-

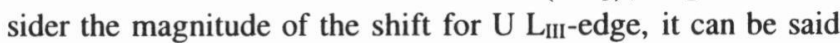
that the oxidation state of Th is not divalent. Unfortunately, no reference materials for Th(III) being available, we cannot conclude whether the oxidation state of $\mathrm{Th}$ in the $\mathrm{C}_{84}$ is $3+$ or $4+$.

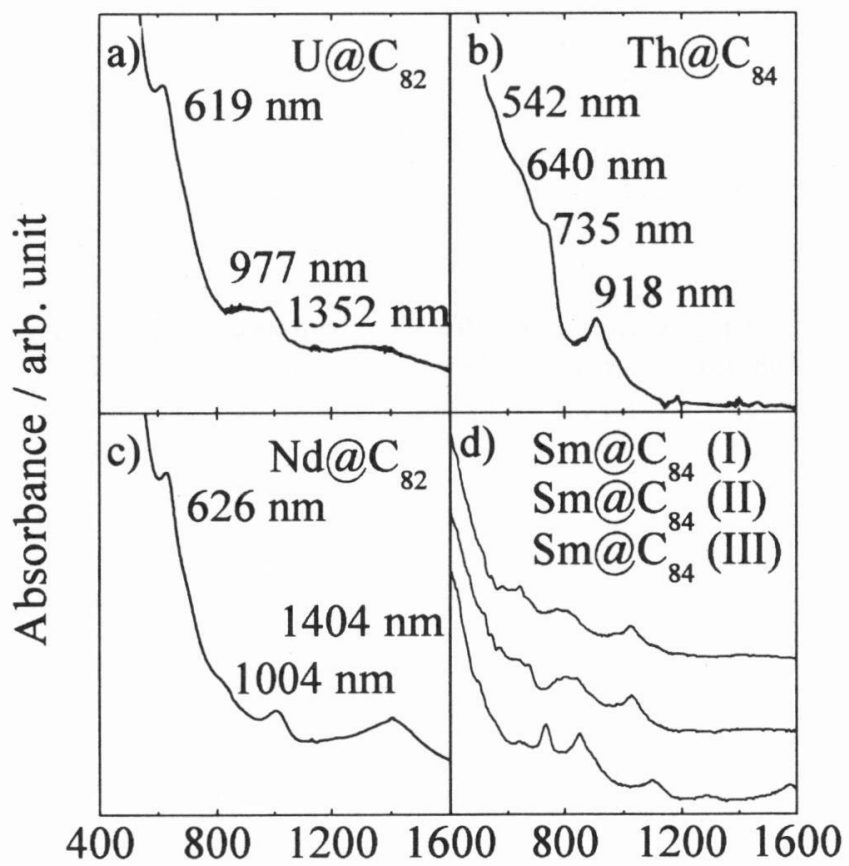

\section{Wavelength / nm}

Figure 2. UV/vis/NIR absorption spectra of isolated (a) $\mathrm{U} @ \mathrm{C}_{82}$ (Ref. 22) and (b) $\mathrm{Th} @ \mathrm{C}_{84}$ in toluene, and those of (c) $\mathrm{Nd} @ \mathrm{C}_{82}$ and (d) $\mathrm{Sm} @ \mathrm{C}_{84}$ in toluene. ${ }^{25}$ 

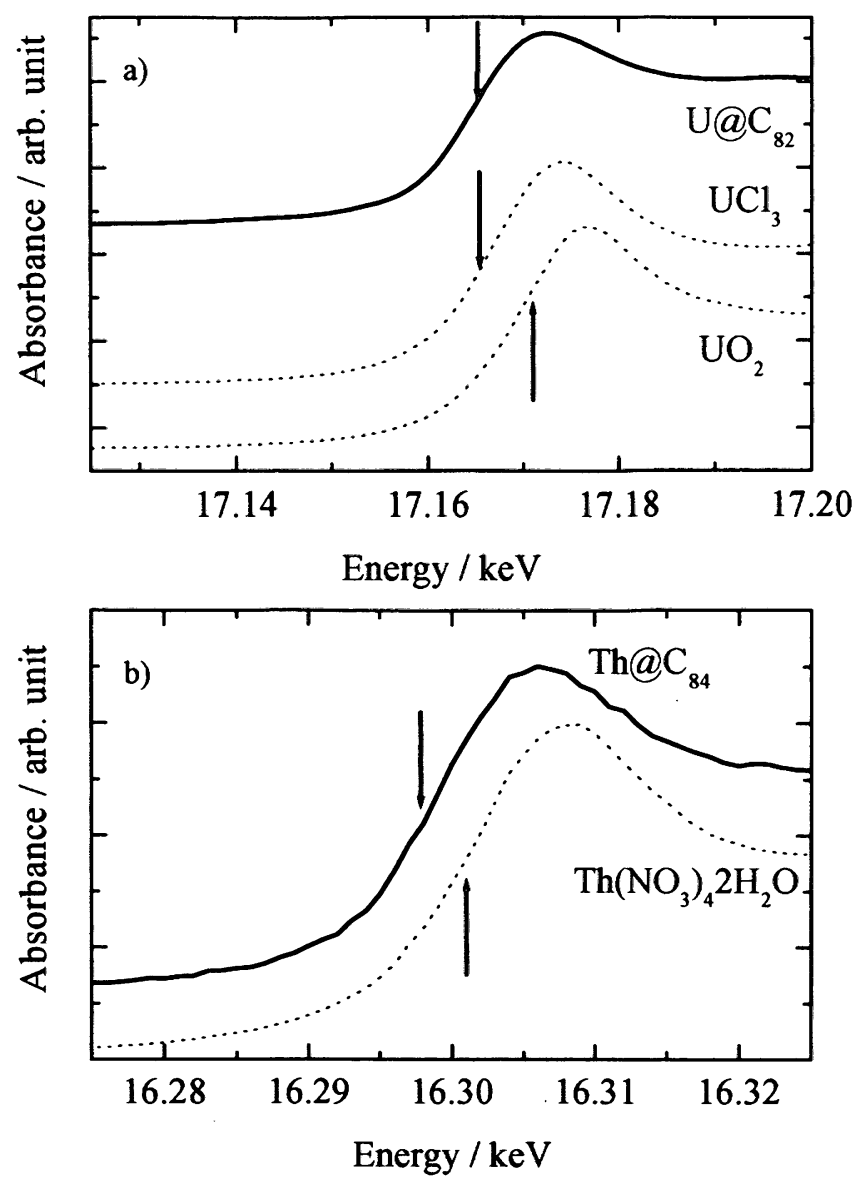

Figure 3. $\mathrm{L}_{\mathrm{m}}$-edge XANES spectra of (a) $\mathrm{U} @ \mathrm{C}_{82}$, (b) Th@ $\mathrm{C}_{84}$, and reference materials of $\mathrm{UCl}_{3}, \mathrm{UO}_{2}$, and $\mathrm{Th}\left(\mathrm{NO}_{3}\right)_{4} 2 \mathrm{H}_{2} \mathrm{O}$. The arrows indicate the absorption edges $E_{0}{ }^{27}$

It can be only mentioned that the Th atom encapsulated in the $\mathrm{C}_{84}$ fullerene is subjected to more reductive chemical environment than that of the nitrate. For Th@ $\mathrm{C}_{84},{ }^{13} \mathrm{C}$-NMR study was also carried out in order to determine the molecular structure of Th@ $\mathrm{C}_{84}$ which will be reported elsewhere. Here we only mention that the ${ }^{13} \mathrm{C}$-NMR spectra could be observed. This fact strongly suggests that no unpaired electron exists on the fullerene cage and, that is, only even number of electrons are transferred from the encapsulated atom to the cage. Thus, we conclude that the oxidation state of Th being $4+$ with the charge of the cage of $\mathrm{C}_{84}^{4-}$.

\section{Conclusion}

The HPLC elution behavior of the actinide metallofullerenes was classified into two groups from the elution curves. The elution curves of the first group, encapsulating $\mathrm{U}, \mathrm{Np}$, and Am, were similar to those of the light lanthanide fullerenes such as $\mathrm{La}, \mathrm{Ce}, \mathrm{Pr}$, and Nd metallofullerenes whose main component was $\mathrm{M} @ \mathrm{C}_{82}$. The UV/vis/NIR absorption and XANES spectroscopy for $\mathrm{U} @ \mathrm{C}_{82}$ revealed that the charge coupling of the metallofullerenes of the first group was $\mathrm{M}^{3+} @ \mathrm{C}_{82}^{3-}$. The elution curves of the second group consisting of $\mathrm{Th}$ and $\mathrm{Pa}$ were different from those of any lanthanides. The chemical species of the main HPLC elution peak of this group was found to be $\mathrm{M} @ \mathrm{C}_{84}$ from the TOF/MS measurements. From the results of the UV/vis/NIR absorption spectra and ${ }^{13} \mathrm{C}$-NMR spectroscopy for Th@ $\mathrm{C}_{84}$, it was suggested that the charge of $\mathrm{C}_{84}$ in $\mathrm{Th} @ \mathrm{C}_{84}$ was $4+$ although the XANES spectroscopy indicated that the Th atom in $\mathrm{C}_{84}$ cage was somewhat more negative than $4+$.

Acknowledgement. This work was partly supported by the REIMEI Research Resources of Japan Atomic Energy Research Institute and by the Grant-in-Aid for the Ministry of Education, Culture, Sports, and Science of Japan. We thank to the crew of the JAERI tandem accelerator for providing the stable ion beam to produce the radiotracers.

\section{References}

(1) H. W. Kroto, J. R. Heath, S. C. O'Brien, R. F. Curl, and R. E. Smalley, Nature 318, 162 (1985).

(2) K. Sueki, K. Akiyama, T. Yamauchi, W. Sato, K. Kikuchi, S. Suzuki, M. Katada, Y. Achiba, H. Nakahara, T. Akasaka, and K. Tomura, Fullerene Sci. Technol. 5, 1435 (1997).

(3) K. Sueki, K. Akiyama, K. Kikuchi, and H. Nakahara, Chem. Phys. Lett. 291, 37 (1998).

(4) K. Sueki, K. Akiyama, K. Kikuchi, and H. Nakahara, J. Phys. Chem. B 103, 1390 (1999).

(5) U. Kirbach and L. Dunsch, Angew. Chem. Int. Ed. Engl. 35, 2380 (1996).

(6) M. D. Diener, C. A. Smith, and D. K. Veirs, Chem. Mater. 9, 1773 (1997).

(7) C. Hao, W. Xu, Z. Liu, X. Guo, and S. Liu, Rapid Commun. Mass Spectrom. 11, 451 (1997).

(8) T. Pichler, M. S. Golden, M. Knupfer, J. Fink, U. Kirbach, P. Kuran, and L. Dunsch, Phys. Rev. Lett. 79, 3026 (1997).

(9) P. Kuran, M. Krause, A. Bartl, and L. Dunsch, Chem. Phys. Lett. 292, 580 (1998).

(10) T. Pichler, M. Knupfer, M. S. Golden, T. Boske, J. Fink, U. Kirbach, P. Kuran, L. Dunsch, and C. Jung, Appl. Phys. A Mat. Sci. Process 66, 281 (1998).

(11) M. Krause, P. Kuran, U. Kirbach, and L. Dunsch, Carbon 37, 113 (1999).

(12) T. Pichler, J. Winter, C. Grazioli, M. S. Golden, M. Knupfer, P. Kuran, L. Dunsch, and L. Fink, Synthet. Metal. 103, 2470 (1999).

(13) M. Krause, M. Hulman, H. Kuzmany, P. Kuran, L. Dunsch, T. J. S. Dennis, M. Inakuma, and H. Shinohara, J. Mol. Struct. 521, 325 (2000).

(14) C. Zhu and J. Yan, Chin. Sci. Bull. 40, 1789 (1995).

(15) W. Andreoni and A. Curioni, Phys. Rev. Lett. 77, 834 (1996).

(16) G. E. Gadd, P. J. Evans, D. J. Hurwood, S. Moricca, G. Mcorist, T. Wall, M. Elcombe, and P. Prasad, Fullerene Sci. Technol. 5, 871 (1997).

(17) J. Q. Ding, N. Lin, L. T. Weng, N. Cue, and S. H. Yang, Chem. Phys. Lett. 261, 92 (1996).

(18) K. Sueki, K. Kikuchi, K. Akiyama, T. Sawa, M. Katada, S. Ambe, F. Ambe, and H. Nakahara, Chem. Phys. Lett. 300, 140 (1999).

(19) J. Q. Ding, L. T. Weng, and S. H. Yang, J. Phys. Chem. 100, 11120 (1996).

(20) J. Q. Ding and S. H. Yang, J. Am. Chem. Soc. 118, 11254 (1996).

(21) K. Akiyama, Y.-L. Zhao, K. Sueki, K. Tsukada, H. Haba, Y. Nagame, T. Kodama, S. Suzuki, T. Ohtsuki, M. Sakaguchi, K. Kikuchi, M. Katada, and H. Nakahara, J. Am. Chem. Soc. 123, 181 (2001).

(22) K. Akiyama, K. Sueki, Y.-L. Zhao, H. Haba, K. Tsukada, T. Kodama, K. Kikuchi, T. Ohtsuki, Y. Nagame, H. Nakahara, and M. Katada, NANONETWORK MATERIALS, edited by S. Saito, T. Ando, Y. Iwasa, K. Kikuchi, M. Kobayashi, and Y. Saito, AIP Conf. Proc. 590 (AIP, New York, 2001), p. 437.

(23) S. Stevenson, P. Burbank, K. Harich, Z. Sun, H. C. Dorn, P. H. M. van Loosdrecht, M. S. deVries, J. R. Salem, C.-H. Kiang, R: D. Johnson, and D. S. Bethune, J. Phys. Chem. A 102, 2833 (1998).

(24) K. Akiyama, K. Sueki, K. Kodama, K. Kikuchi, I. Ikemoto, M. Katada, and H. Nakahara, J. Phys. Chem. A 104, 7224 (2000).

(25) T. Okazaki, Y. F. Lian, Z. N. Gu, K. Suenaga, and H. Shinohara, Chem. Phys. Lett. 320, 435 (2000). 
(26) Isolated Pentagon Rule (IPR): that is the rule to explain the stability of the cage like structure of fullerenes. Each five membered in the most stable cage are never adjacent to each other.
(27) K. Akiyama, K. Sueki, H. Haba, K. Tsukada, M. Asai, T. Yaita, Y. Nagame, K. Kikuchi, M. Katada, and $\mathbf{H}$. Nakahara, J. Radioanal. Nucl. Chem. (in press). 